\title{
PENGARUH PENERAPAN E-LEARNING TERHADAP PRESTASI BELAJAR MAHASISWA (STUDI KASUS PADA MAHASISWA JURUSAN AKUNTANSI FAKULTAS EKONOMI DAN BISNIS UNIVERSITAS SYIAH KUALA)
}

\author{
Reni Suendari*1, Suparno*2 \\ ${ }^{1,2}$ Program Studi Akuntansi Fakultas Ekonomi dan Bisnis Universitas Syiah Kuala \\ e-mail: renisuendari@gmail.com*1, suparno.feakt@ unsyiah.ac.id ${ }^{* 2}$
}

\begin{abstract}
The aim of this study is to examine the effect of using e-learning tools on students achievement in learning who are majoring in accounting at Faculty of Economics and Business, Syiah Kuala University. This research uses quantitave research approach with the type of case study. The data used in this study is primary data by distributing questionnaires directly to all respondents. The population in this study is all students who are majoring in accounting at Faculty of Economics and Business, Syiah Kuala University. The sampling technique used in this study is Judment sampling. The number of questionnaires that have been analyzed are 33 questionnaires. Testing the effect of independent variable on the dependent variable was done by using simple linear regression model with SPSS. The result of this study indicates that the use of e-learning has a positive effect on students achievement in learning who are majoring in accounting at the Faculty of Economics and Business, Syiah Kuala University.
\end{abstract}

Keywords: E-Learning, Students Achievement.

\section{Pendahuluan}

Perkembangan teknolgi di Indonesia semakin meningkat tiap tahunnya, hal tersebut dapat dilihat dari survey pada APJII. Pada tahun 1969 internet hanya digunakan untuk keperluan militer saja, akan tetap pada saat ini internet dapat digunakan oleh semua pihak agar memudahkan mereka dalam mencari informasi. Kementrian Riset Teknologi dan Pendidikan Tinggi yang bergerak pada bidang organisasi fungsinya untuk mengelola pendidikan tinggi di Indonesia.

Teknologi informasi dan komunikasi yang berkembangan pada saat ini, disambut baik dalam dunia pendidikan. Perkembangan teknologi tersebut harus di terapkan didalam dunia pendidikan agar dapat menghasilkan mahasiswa-mahasiswa yang paham akan ilmu pengetahuan, mereka harus mampu merefleksikan pengetahuan tersebut dengan keadaan saat ini. Oleh karena itu, perlu dilakukan sebuah pembangunan berkelanjutan dalam dunia pendidikan tinggi. Pembangunan dalam dunia pendidikan merupakan respon yang dapat dilihat dari etika keilmuan (Abbas, 2013).

Mahasiswa dituntut untuk aktif dalam meningkatkan kinerja individu terhadap penerapan teknologi informasi yang dari tahun ketahun mengalami peningkat sangat pesat, dengan adanya perbedaan karakteristik pemakaian secara individu dapat mengakibatkan perbedaan dalam pencapaian tujuan, sehingga dapat mempengaruhi masing-masing individu, kinerja atau prestasi belajar mahasiswa.

Proses belajar-mengajar yang bersifat konvensional atau hanya mengandalkan tatap muka saja, rasanya kurang optimal dikarenakan saat penyampaian materi mahasiswa kurang dapat memahaminya. Mahasiswa akan sulit untuk meningkatkan prestasi belajar mereka, apabila dalam memahami materi saja dirasakan sulit bagi mahasiswa. Kondisi ini merupakan masalah yang akan semakin sulit dipecahkan jika proses belajar-mengajar tidak diperbaharui (Niswati, Donna, Lestari, \& Gustyani, 2016).

Perubahan proses belajar-mengajar yang dapat dilakukan saat ini salah satunya yaitu dengan menggunakan teknologi yang ada, seperti memanfaatkan e-learning. E-learning didunia pendidikan akan sangat membantu kebutuhan informasi yang dibutuhkan oleh penggunanya. Informasi yang ditampilkan dalam penerapan $e$ learning untuk pendidikan merupakan terobosan yang sangat strategis dalam penerapkan teknologi baru pada 
kegiatan sistem informasi didunia pendidikan (Hanum, 2013).

E-learning merupakan penggunaan dari sebuah alat teknologi beruapa jaringan internet. Dengan adanya e-learning materi dapat diakses dimanapun dan kapanpun hanya dengan adanya koneksi jaringan internet, sehingga metode pembelajaran lebih efektif tidak hanya terpaku didalam ruang kelas dan dijam tertentu saja, namun bisa digunakan diluar kelas dan dijam yang tidak terbatas (Nu'man, 2014).

E-learning berperan dalam pengurangan biaya (cost) operasional pada institusi pendidikan, dikarena tersediannya materi di website. Dengan adanya $e$ learning kegiatan belajar tetap dapat dilakukan meskipun mahasiswa dan dosen tidak berada didalam ruangan kelas, dan bagi mahasiswa yang tidak dapat hadir tidak perlu takut akan tertinggalnya materi perkulihan yang dapat menyebabkan menurunnya prestasi belajar mahasiswa (Agustin \& Mulyani, 2016).

Prestasi merupakan tolak ukur yang dijadikan untuk mengetahui kemampuan mahasiswa dalam belajar, seseorang yang mendapat nilai yang tinggi dapat dikatakan telah berhasil dalam proses pembelajar. Prestasi belajar memiliki arti yang berbeda dan saling berhubungan erat. Setiap proses pembelajaran akan menghasilkan prestasi belajar yang miliki perbedaan dari setiap individunya (Novius, 2012).

Untuk dapat meningkatkan prestasi belajar mahasiswa, ada beberapa cara dalam proses belajar seperti, memerlukan suatu media yang dinamakan sebagai media pembelajaran. Dengan adanya media pembelajaran segala sesuatu dapat dilakukan dengan mudah, dapat menyalurkan pesan, dan dapat mendorong terciptanya proses belajar pada mahasiswa (Prihati \& Paramita, 2016).

\section{Kajian Pustaka}

\section{Sistem Teknologi Informasi}

Sistem merupakan sekumpulan unsur yang saling berhubungan dan berkerjasama antara satu dengan yang lainnya dalam pencapaian tujuan tertentu. Menurut Yazdi (2012) teknologi informasi merupakan gabungan dari beberapa alat untuk menghubungkan perangkat komputer dan internet yang nantinya akan memudahkan kita dalam mencari informasi. Sehingga dapat ditarik kesimpulkan bahwa sistem TI, yaitu seperangkat komponen yang saling berhubungan dan bekerjasama untuk mencari sebuah informasi tertentu.

Dalam aktivitas pembelajaran, teknologi informasi berperan sangat besar. Perubahan metode pembelajaran memberikan andil yang besar terutama dalam kegiatan belajar mengajar yang dijadikan sebagai fasilitator utama. Adanya sistem teknologi informasi ini dapat dijadikan sebagai acuan dalam perubahan proses belajar-mengajar, salah satu perubahan yang terjadi adalah lahirnya aplikasi yang mulai digunakan untuk mempermudah dosen dalam melaksanakan proses belajar-mengajar (Hanum, 2013).

\section{Control System}

Menurut Agustin, (2013) Sistem adalah susunan komponen fisik yang terhubung atau terkait sedemikian rupa sehingga membentuk atau bertindak sebagai seluruh unit dalam satu kesatuan. Sedangkan kata kontrol biasanya diartikan mengatur, mengarahkan, atau perintah. Jadi dapat ditarik kesimpulan bahwa sistem kontrol adalah suatu susunan komponen fisik yang terhubung atau terkait sedemikian rupa sehinga dapat memerintah, mengarahkan, atau mengatur diri sendiri atau sistem yang sedang berjalan. Control system juga dapat diartikan sebagai pengawas berjalanan suatu kegiatan yang dilakukan oleh individu.

Control system digunakan dalam dunia pendidikkan untuk dapat membantuk dalam melaksanakan proses pembelajaran agar memudahkan semua pihak dalam menjalankannya, denagan control system ini dapat melihat, mengarahkan, dan mengatur mahasiswa dalam mengikuti proses belajar-mengajar dengan baik. Universitas Syiah Kuala sudah memiliki suatu aplikasi yang dapat mengontrol proses pembelejaran.

Aplikasi yang digunakan adalah e-learning, aplikasih ini mempermudah dosen dan mahsiswa dalam pembelajaran, dengan adanya e-learning proses pembelajaran bisa dilakukan dengan jarak jauh. Elearning memberi peran sangat besar dalam metode pembelajaran, mahasiswa dapat lebih giat untuk belajar, mempermudah mahasiswa untuk memperoleh materi perkuliahan, dan dapat membantu mahasiswa dalam meningkatkan prestasi belajar (Prihati \& Paramita, 2016). 


\section{E-Learning}

Kepanjangan dari e-learning adalah electronic learning, metode pembelajaran yang dibantu dengan perangkat elektronik menggunakan media komputer dan jaringan internet. Perubahan metode pembelajaran dijadikan sebagai batu loncatan didalam dunia pendidikan (Nu'man, 2014). Dalam dunia pendidikan alat teknologi yang diterapkan adalah e-learning, penggunaan electronic learning merupakan proses instruksi dalam menyampaikan, menilai dan memudahkan proses belajar mengajar (Hidayat, 2013).

E-learning berkontribusi untuk mengurangi biaya (cost) seperti biaya operasional pada institusi pendidikan tinggi, dikarena tersedianya materi perkuliahan di website (Agustin \& Mulyani, 2016). Elearning juga dapat mengurangi biaya bagi mahasiswa/i dan dosen.

\section{Prestasi Belajar}

Menurut Aminoto \& Pathoni (2014) bahwa prestasi belajar adalah sesuatu yang dapat menciptakan sebuah hasil yang menyenangkan hati seseorang, prestasi belajar itu sendiri adalah suatu hal yang sangat penting bagi seseorang, dikarenakan prestasi belajar itu sendiri dapat dijadikan sebagai bahan evaluasi. Evaluasi bertujuan untuk mengetahui sejauh mana seseorang itu mengusai materi yang telah disampaikan.

Dari penejelasan diatas dapat ditarik kesimpulkan bahwa prestasi belajar adalah sebuah hasil yang dapat dilihat dari score atau nilai setelah mengikuti proses belajar mengajar. Score atau nilai diperoleh oleh seseorang jika telah mengerjakan tugas sesuai dengan tentuan yang berlaku.

\section{Metode Penelitian}

\section{Desain Penelitian}

Desain penelitian adalah sebuah bagian dari rencana penelitian yang dibuat agar penelitian yang dilakukan oleh peneliti berjalan sesuai rencana dan menghasilkan penelitian yang valid, objektif, tepat dan hemat. Desain penelitian mengenai studi kasus menjelaskan secara mendalam atau mempelajari secara intensif suatu anggota atau individu dari sasaran objek yang akan diteliti. Pendekatan kuantitatif digunakan dalam penelitian ini, penelitian kuantitatif adalah penelitian yang berasas pada filsafat, serta bergunakan dalam penelitian untuk mengambil populasi (Suharso, 2009).

\section{Populasi dan Sampel Penelitian}

Populasi adalah keseluruhan dari karakteristik yang telah ditetapkan untuk merujuk kepada kelompok, kejadian, orang atau minat pada seseorang yang ingin diselidiki oleh peneliti untuk dipelajaran dan disimpulkan, sedangkan sampel adalah bagian dari populasi yang ada (Sekaran \& Bougie, 2013:240). Populasi pada penelitian ini diantaranya mahasiswa aktif prodi S1 akuntansi Fakultas Ekonomi dan Bisnis Universitas Syiah Kuala. Populasi dalam penelitian ini berjumlah 77 responden yaitu seluruh mahasiswa angkatan 2015 yang terdata pada jurusan akuntansi.

\section{Data dan Teknik Pengumpulan Data}

Data yang akan digunakan dalam penelitian ini adalah data primer. Data primer meupakan data yang diperoleh berdasarkan penyebaran kuesioner kepada semua mahasiswa yang dijadikan sebagai sampel dan responden dalam penelitian. Pengumpulan data dilakukan dengan cara membagikan kuesioner. Kuesioner merupakan metode pengumpulan data yang dilakukan dengan cara memberi sekumpulan pertanyaan atau pernyataan tertulis kepada responden untuk dijawabnya (Sugiyono, 2013:193).

\section{Metode Analisis}

Metode analisis regresi linear sederhana berfungsi untuk menguji pengaruh 2 variabel yaitu VI dan VD. Dalam penelitian ini variabel independennya adalah penerapan e-learning (X), sedangkan variabel dependennya adalah prestasi belajar mahasiswa (Y).

Metode analisis ini digunakan untuk menguji "pengaruh penerapan e-learning terhadap prestasi belajar mahasiswa jurusan akuntansi Fakultas Ekonomi dan Bisnis Universitas Syiah Kuala”. Model ini dipilih karena penelitian ini hanya menggunakan 2 variabel yaitu 1 variabel bebas dan 1 variabel terikat. Analisis data penelitian ini akan diolah menggunakan bantuan SPSS (statistical package for social scrence), dengan model persamaan regresi sebagai berikut :

$$
\mathbf{Y}=\mathbf{A}+\mathbf{B X}+\mathbf{e}
$$

Keterangan :

$\mathrm{Y}=$ Prestasi Belajar

$\mathrm{A}=$ Konstanta

$\mathrm{B}=$ Koefisien Regresi

$\mathrm{X}=$ E-Learning

$\mathrm{e}=$ Error 


\section{Hasil Penelitian}

\section{Hasil Pengujian Hipotesis}

Pengujian secara parsial berguna untuk melihat seberapa pengaruh VI terhadap VD secara individual. Pengujian ini juga berguna untuk mengetahui seberapa besar pengaruh penerapan $e$-learning terhadap prestasi belajar mahasiswa jurusan akuntansi Fakultas Ekonomi dan Bisnis Universitas Syiah Kuala. "Jika $\mathrm{T}_{\text {Hitung }}>\mathrm{T}_{\text {Tabel }}$ dengan tingkat signifikan $5 \%$ menunjukkan bahwa secara parsial VI berpengaruh secara signifikan terhadap VD. Berdasarkan tabel 4.8 nilai $\mathrm{T}_{\text {Hitung }}$ penerapan e-learning adalah 2,999 sedangkan nilai $\mathrm{T}_{\text {Tabel }}$ 2,03, seperti yang telah dijelaskan sebelumnya jika $\mathrm{T}_{\text {Hitung }}>\mathrm{T}_{\text {Tabel }}$ dengan tingkat signifikan $5 \%$ maka $\mathrm{h}_{0}$ ditolak, ini berarti berarti penerapan e-learning mempunyai pengaruh signifikan terhadap prestasi belajar.

\section{Pembahasan}

\section{Pengaruh Penerapan E-Learning Terhadap Prestasi Belajar}

Berdasarkan hasil regresi linear sederhana, nilai koefisien regresi menunjukkan bahwa penerapan $e$ learning berpengaruh terhadap prestasi belajar mahasiswa jurusan akuntansi Fakultas Ekonomi dan Bisnis Universitas Syiah Kuala. "Hasil ini telah sesuai dengan hipotesis yang telah disusun, yaitu penerapan e-learning berpengaruh terhadap prestasi belajar mahasiswa jurusan akuntansi Fakultas Ekonomi dan Bisnis Universitas Syiah Kuala”.

\section{Kesimpulan dan Saran \\ Kesimpulan}

Berdasarkan dari hasil pengujian hipotesis menunjukkan bahwa penerapan e-learning memiliki pengaruh signifikan terhadap prestasi belajar mahasiswa jurusan akuntansi Fakultas Ekonomi dan Bisnis Universitas Syiah Kuala.

\section{Saran}

1. Penelitian selanjutnya disarankan agar menambah berbagai variabel lainnya yang dapat mempengaruhi penerapan e-learning terhadap prestasi belajar mahasiswa jurusan akuntansi Fakultas Ekonomi dan Bisnis Universitas Syiah Kuala. Seperti variabel motivasi, kinerja belajar dan lain-lainnya.
2. Penelitian selanjutnya lebih baik diarahkan untuk membandingkan prestasi belajar sebelum dan sesudah menggunakan e-learning atau membandingkan 2 metode yaitu metode penerapan e-learning dan metode secara konvensional tetapi penerapan itu harus digunakan pada mata kuliah yang sama agar dapat dilihat metode mana yang dapat meningkatkan prestasi belajar mahasiswa.

\section{Daftar Pustaka}

Abbas, W. (2013). Analisis Sikap Mahasiswa Terhadap Pemanfaatan E-Learning ( Studi Kasus Fakultas Teknik Uny ). Seminar Nasional Teknologi Informasi Dan Komunikasi 2013 (Sentika 2013), (Sentika).

Agustin, H., \& Mulyani, E. (2016). Studi Empiris Penerimaan Dan Penggunaan E- Learning System Di Kalangan Mahasiswa Akuntansi Fakultas Ekonomi Unp. Seminar Nasional Aplikasi Teknologi Informasi (Santi), 5(3), 1722.

Agustian, Indra. 2013. Definisi Sistem Kendali. 04 juni. Diakses Februari 10, 2015. http://te.unib.ac.id/lecturer/indraagustian/ 2013/06/definisi-sistem-kendali/.

Aminoto, T., \& Pathoni, H. (2014). Penerapan Media E-Learning Berbasis Schooloogy Untuk Meningkatkan Aktivitas Dan Hasil Belajar Materi Usaha Dan Energi Di Kelas Xi Sman 10 Kota Jambi. Jurnal Sainmatika, 8(1).

Hanum, N. S. (2013). Keefektifan E-Learning Sebagai Media Pembelajaran (Studi Evaluasi Model Pembelajaran E-Learning Smk Telkom Sandhy Putra Purwokerto). Jurnal Pendidikan Vokasi, 3(1), 90-102.

Hidayat, A. (2013). Pengaruh Penggunaan E-Learning Terhadap Motivasi Dan Efektivitas Pembelajaran Fisika Bagi Siswa Sma. Journal Of Chemical Information And Modeling, 53, 160.

Niswati, I., Donna, Lestari, P., \& Gustyani. (2016). Hubungan Antara Metode Online Learning (ELearning) Dengan Motivasi Berprestasi Mahasiswa Universitas "Xx." Universitas Bunda Mulia, 2(1), 23-39.

Novius, A. (2012). Faktor-Faktor Yang Mempengaruhi Prestasi (Studi Empiris Mahasiswa Yang Berprestasi Jurusan Akuntansi Fakultas Ekonomi Dan Ilmu Sosial Universitas Islam Negeri Sultan Syarif Kasim Riau). Fokus Ekonomi, 7(2), 97-111.

Nu'man, A. Z. (2014). Efektifitas Penerapan ELearning Model Edmodo Dalam Pembelajaran 
Pendidikan Agama Islam Terhadap Hasil

Belajar Siswa (Studi Kasus: Smk

Muhammadiyah 1 Sukoharjo). Journal Of

Chemical Information And Modeling, 7(9), 1689-1699.

Prihati, Y., \& Paramita, P. (2016). Efektifitas Pemanfaatan Media Pembelajaran Berbasis Komputer Untuk Meningkatkan Hasil Belajar Ipa Pada Siswa Tunagrahita. Media Penelitian Pendidikan, 10(2), 199-210.

Sekaran, \& Bougie. (2013). Research Methods For Bussines: A Skill-Building Approach. Jakarta.

Sugiyono. (2013). Metode Penelitian Kuantitatif, Kualitatif, Dan Kombinasi (Mixed Methods). (M. T. Sutopo, Ed.) (Prof. Dr.). Bandung: Alfabeta.

Suharjo, P. (2009). Metode Penelitian Kuantitatif. Jakarta: Pt Indeks.

Tomo, S., \& Widada, B. (2015). Pengaruh Pemanfaatan E-Learning Terhadap Prestasi Belajar Mahasiswa (Studi Kasus Stmik Sinar Nusantara Surakarta) Sri Tomo, Bebas Widada. Jurnal Ilmiah Sinus, 35-44.

Yazdi, M. (2012). E-Learning Sebagai Media Pembelajaran Interaktif Berbasis Teknologi Informasi. Jurnal Ilmiah Foristek, 2(1), 143152. 